\title{
THE IMPACT OF THE RESIDENT'S PARTICIPATION IN IMPROVING DESIGN AND HOME CONSTRUCTION PROCESS
}

\author{
Ali Behrad Manesh \\ Engineer, Master of Architecture, School of Architecture Science and Research Branch of Islamic Azad \\ University. Zahedan \\ behrad1985@gmail.com \\ Esfandiar Azizi \\ Architect, Master of Architecture, School of Architecture. Noor University \\ espaand@yahoo.com
}

\begin{abstract}
Considering the characteristic of human in that they failed to meet the needs of its residents in recent years has become a public demand. The architect's role as the sole decision-making authority for the design environment is gradually changing and the needs of users, Demands and interests that provide opportunities for individuals working in the project. This led to a paradigm shift in the architectural Schema. So when trying to engage users with different people or in planning. The approach under various titles such as participatory design, user design, etc. Is introduced. The aim of this study was to obtain more desirable homes with residents to cooperate in the process of design and construction. One of the most important needs of home residents have their mental health needs And a place in the human mind develops always include cognitive represent different angles are viewed. Today, collaborative design or design as the foundation of a new paradigm in the design process, creativity is manifested Theoretical and scientific aspects of the recall and recognition of the central purpose of this research. Houses should be designed to suit the needs of residents this is not possible unless before designing and consulting with residents to ask them. And ideas in a logical and consistent design to be used.
\end{abstract}

Keywords: Participatory design; Ideas residents in Design; home design

\section{INTRODUCTION}

Architecture and urbanism in the present era are strongly influenced by the hasty adoption of the principles and concepts of modernity's value and in the meantime, the concept of residence is mix with the concept of staying and it was assumed that House-building process should only terminate to improve and Housing reform process in order to respond to the thinking quick yielding.

Thought that believes the only way to overcome the housing crisis is mass production. In this process, the individual needs and mental demands and intellectual characteristics and residents attitudes, victims of quickly growing of uniform and meaningless house building. The research endeavors to participate in the noble meaning of the original word as correct in the restoration of housing, the actual position and its cultural assist and converters the house to be safe and secure place. This research is based on promoting human values and cultural perspective, from the perspective of evidence-based practices and case study analysis and In terms of result, therefore, can be considered as a functional survey.

\section{Hypotheses:}

The main issue is based on "the reflection of the participation of residents and designer in the design of the house" that we express it: How can we achieve to a more desirable designing and building homes by 
participating of residents in the design process? Accordingly, a number of questions can be raised based on diversity of participation applications in architecture and it's reflects that presented as follows:

1. With participation of the designer and resident of the house, in the design and construction of their homes, can be achieved to the best plans and architectural drawings for people.

2. Architect or designer could use the residents of the house viewpoint, and create the best ideas and designs based on the mood of the residents

"And Allah gave you houses for habitation, and made for you of the skins of cattle some houses which are light for the day you travel and for the day you stay at stage, and from their wool and fur and hair some household goods and the things of use for a time. (Surah An-Nahl, verse 80)"

\section{Housing from the Islamic perspective}

In the Qur'an, the housing is mentioned as a place for relaxation and binding, which means that housing plays a role in the training of human and he approaching God, and effects the manner of human and this effect leads him to understanding the blessings of the Lord.

Home becomes a safe environment in term of psychologically that have the ability to respond to higherlevel of human requirement like self-actualization and thought.

In Islam and Quranic verses emphasis on the importance of residential homes, to achieve spiritual peace. The main result of serenity, spirituality of home space, ability to accommodate and the ability to respond to the spiritual needs of human beings, such as thinking, presence and peace of heart.

\section{Home (housing)}

Today instead of using the house sometimes is used the home and this word in the past, was called to the room.

Housing is an extensive and complex concept, and has different dimensions, so it cannot present the comprehensive definition of it. Housing is considered as a physical location and basic shelter and essential household. In this shelter are provided some of the basic needs of families, such as sleep, rest, protection from weather conditions and the summary of living conditions.

The first definition: "home is coverage that is consistent with some of the conditions of the proper relationship between the external environments and establishes the human biological phenomena. An individual or a family must live in the home. That is, sleep, walk, lie down, and see and think. "(Le Corbusier)

The second definition: "Home is the center of the world that for its citizens and its neighborhood is the most prominent building in the consolidation place" (Moore)

The third definition: the house in the first place is an institution and not a structure and this institution has been created for many complicated purposes. Since the construction of a house is a cultural phenomenon ... "(Rappaport)

Fourth definition: home is a place that residents don't feel upset and inside the houses that women and children are living there should have variety that they do not feel fatigue "(Pirnia)

In the following is referred to the basic principles with values for designing homes that should be carefully discussed.

1. Environment: none of the architectural work cannot and should not be made without regard to its surroundings because the environment has a significant effect on residential architecture.

2. People: Human in architecture are the most important factor and also the architecture is dependent that this effect provides maximum comfort of people and is more efficient in response to human needs. (Kiani, Mohammad Yousuf, 2005) Architecture for people and attention to the audience to design the building as an important concept and architect should be imprinted in their mind. Proportions and human scale in urban planning and architecture plays an important role in regard to these issues with regard to the use of local materials and in harmonious with the surrounding nature and it also added to the beauty of the buildings and urban, thus creating the 
spaces takes advantage In human dignity that, regulation the golden proportions, dimensions and size of spaces and reveals it to the best possible. (PirNia, Mohammad Karim, 1995)

3. Facilities: take attention or lack of attention to materials and methods of construction and the use of correct or incorrect concepts and form template method causes the success or failure of an architectural work.

4. Sizes and Standard: This parameter is considered from two directions and can be determined one of the responses to the human body needs and the other is its effect on the human psyche.

5. Spatial regulation: residential architecture is realized of its nature and because of this in such spaces, also needs to the spatial regulation.

6. Visual art qualities: beauty considerations cannot be installed on architecture or hung from it. Architectural beauty is something that must come from within and outside of it. (Kiani, Mohammad Yousuf, 2005)

House in the past on the one hand is the center of feelings, emotions, thoughts and personal and family relationships, and on the other hand is reflection of the culture of its time. Traditional houses design is targeted of the human spirit and has played an effective and essential role in promoting human presence in the family and society.

\section{New world and new architecture}

The overall goal of the modern architecture is taking place of the new settlement of human. The new settlement must satisfy the human need identification and thus the expression new "rapport" between humans and the environment. Le Corbusier in 1923 wrote: "home issue, is a new era issue.", "Social balance depends on this issue. Architecture, in the modernization era, is the first task that was to revise the values and elements of the house."

Many times, the modern architecture pioneers, recognized the modern world, and emphasized that architecture cannot apply to the past forms. In this regard, Le Corbusier has well-known slogan: "An important era has begun. There is a new spirit ... are suppression architectural traditions and customs. "Styles" are lies ... our era, and style are determined day to day. "And" Mysundroheh »added:" Not yesterday, not tomorrow, but can be determined form only in the present. "The idea that was expressed was regardless of political beliefs ..." as a result, the architecture must act again, and this goal was not raised before this century.

In 1914, Antonio Sent Elia, follower of futurism said: "Architecture break down with tradition; it is necessary that the architecture begin again. Bitter conflict reveals that between modern and old world with something that there wasn't before ..." all comments that quotes, back to the moderate and unadorned questions to 1826 : "do not try to find our style?"

All these theories are induced somehow less attention or perhaps neglect of human in the architectural environment.

While in modern architecture because it puts life into helping humans and in the new world feel comfort like their home. The concept of this feeling of comfort, is beyond the need for shelter, cloth and food; and in the first instance this concept is to identify with the natural and social environment. This concept is also a sense of belonging and participation, this means that familiar and understood world possession. Man must feel exposed to known, meaningful and with the identity things. We are all aware that this identity in the modern world becomes problematic. Confined and secure spaces have collapsed, and seek to the new structures. In today architecture, have been ignored the most important criterion that is culture, customs and people.

\section{Culture and its impact on architecture}

Human is a creature that has been dominating to the nature through the culture and from the barbarism has reached to the modern civilized society. Sir Edward Burnett Tylor, English Anthropologist, in 1871 
(Assyrian, 2002) with the publication of Primitive Culture book, proposed culture as new scientific means in anthropology, but this knowledge was not used until 1920.

Cultures were used in the traditional sense it means to civilization, and human culture is known based on their behavior, food, music, art and literature that had special characteristics, While Taylor has been introduced culture as science, religion, art, morals, customs and any human ability and habits that binding the human to the certain groups of communities that is a comprehensive definition of culture. New concept of culture emerged when the need for understanding the culture and the meaning of life and human behavior became necessary because the concepts of natural science were not clear for natural and biological phenomena for human behavioral, so that cannot present human behavior based on the needs and biological mechanisms such as the need for food or shelter for the survival of the individual. Because human vital needs are such as the animal's need, while requirement in the human world take the complex form with the combination of the values, ideals, expectations, ethics, and traditions.

Culture is divided into two parts: 1 . Material Culture 2 - spiritual culture

Material culture: includes all equipment and material instruments and what is man-made from natural material and their methods and construction processes.

Spiritual culture: including values, visions, beliefs, ideas, knowledge and technology, customs and traditions, science, philosophy, literature and art and all products of the human mind. (Khakban, M., and M. Rajabi)

In fact architects are not depend on the building strength and the amount of cement and iron. Architecture essentially requires people's culture, and this is the old architecture and traditional definition of the Iranian people. (Ibid., P. 20)

For example, the Iranian specific beliefs have influenced on the formation of various architectural spaces, particularly in residential areas.

\section{Chandigarh, a sample of an unsuccessful task:}

Le Corbusier After years of trying in Rio de Janeiro, Algeria, san die and Bogotá, in 62 years old to find this rare opportunity to practical his theories on a large scale to design a new city. Chandigarh was raised after the independence of India in 1947 in order to accommodate west Punjab and the main requirements of the city and should become the most important and basic work, because his plan was the only real urban design that he implement it. Le Corbusier generally did not dispute the average residential units, and don't forget the correlation problem, and defined their units as Panorama village with internal streets. Today cannot agree with the vertical village idea, but before this idea to be forgotten, it should compare it at least with the past villages that have been made in areas with steep. Chandigarh with its separation from the city, almost become a forbidden zone for most of the citizens who expect him to the glory of its architecture. Due to the great distance of the Capitol buildings that had been converted into separate units. But what happened on Chandigarh is not consistent with Le Corbusier dream. Each of the buildings has remained apart from the city and its people. For security reasons, surrounded and isolated with fence and barbed wire. The product is nothing except extensive and impressive concrete areas. By walking through the remained area between the buildings with rough and worn surfaces, Capitol induces the effect of annoying downtime as if it has been frozen since its inception. However, finally, it seems that the interests of Le Corbusier as an artist varied with Shandygar citizens interests. Human feels with the same approach and to prefer more lifetime and Shandygar residents due to the enhancing their intuitive knowledge in the field of architecture, was enduring source of imagination and vitality for him, appreciative of him.

What cannot be seen in this town that has brought many problems are attention to pedestrian and human scale that are missing from the modern cube-shaped building of the cities and by ignoring the human and spiritual needs and violation of traditional norms and rituals.

If we look at the project from a professional point of view, we should say that today's complex requirements and technical demands of much modern architectures, it's seems impossible that a designer to undertake such a huge task. Le Corbusier as observers say, during the design insist on solving all the 
problems of the buildings without attention to the expert opinion. He also fears that others ideas influence or import on his opinion, and refused of any dialogue about current trends on the project. While Le Corbusier at all stages are willing to take bold risks, but neither city, nor buildings, have not been successful in practice.

He failed takeover on the climate, including hot and monsoon winds appropriate use of non-insulated concrete. Similarly, in urban scale, separation and differentiation pathways and streets with zoning regulations, is not encouraging for lively and dynamic activities. Inflexible nature of the city provides images from metropolitan Abadi.

Le Corbusier in his book entitled The City of Tomorrow (1937), shows a blank rectangular that this sentence is written in "to be kept empty for the work that expresses modern feeling". Le Corbusier take attention to design of that area, it was hoped that he, himself, adequately responses to the needs of the urban space in the Capitol of Chandigarh. However, like many interesting ideas, his attention is influenced by architects of different generations, Chandigarh because of what it could be, has important, not what it is today.

Encountered problems due to the lack of proper understanding of designer of scale and nature of the project, causes of this failure that of course, all of them does not detract from the great history of Le Corbusier and nowadays he has been a source of inspiration not on his victory, but in his defeat.

\section{Jibaou cultural center as a sample of successful task:}

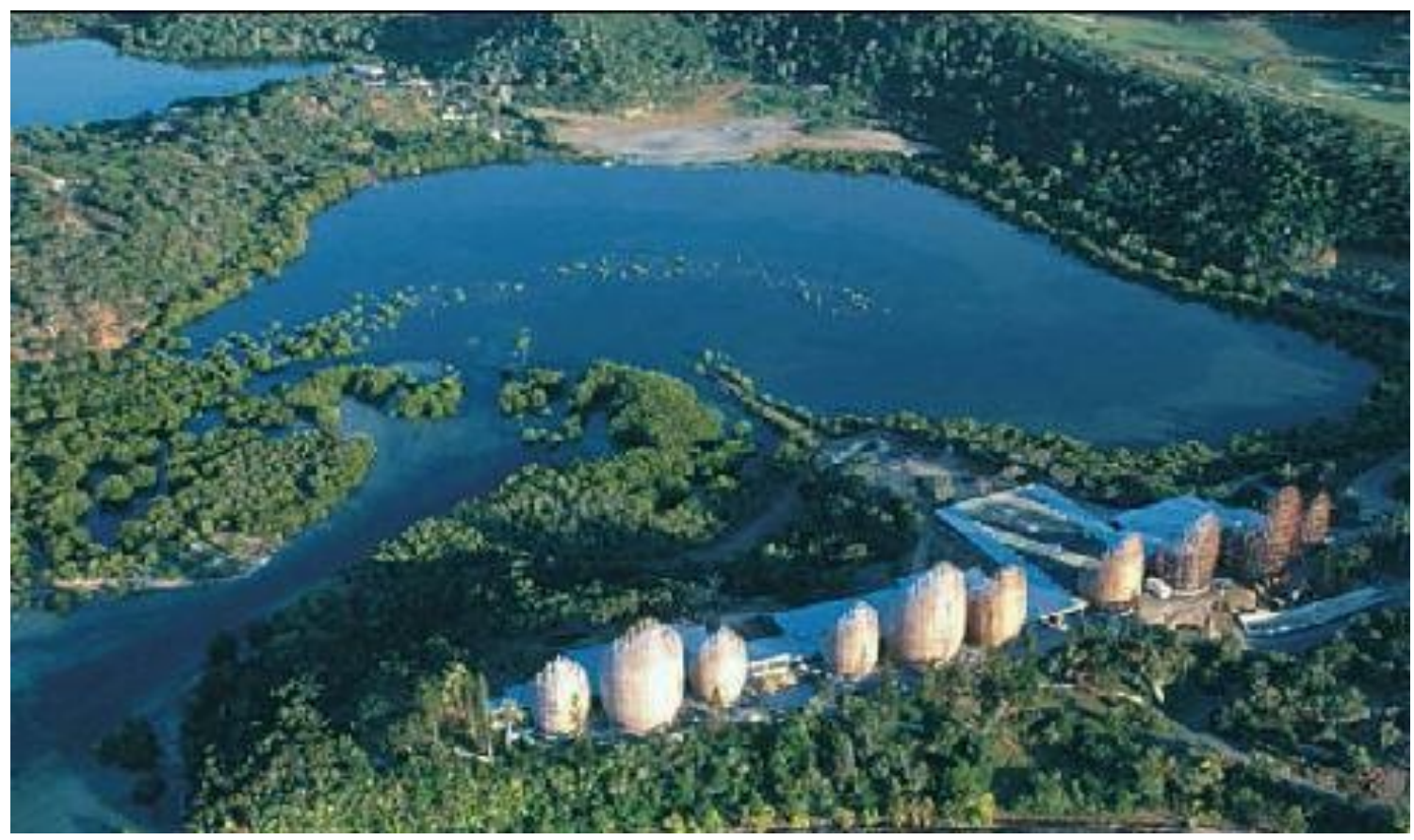

http://iwankhaneyememary97.blogfa.com/post/28

New Caledonia Islands has a land area of $18,575 \mathrm{~km}^{2}$ and a population of about 216000 people in the western waters of the Pacific Ocean and in the 1500 kilometers of the east coast of Australia. Nouméa is a center. The islands are volcanic and mountainous. Roamer English in 1774 called it "New Caledonia" because of his resemblance to the scenery in Scotland Caledonia. Climate: Warm and wet and rainy and it soil is suitable for agriculture. Its Islands has dense vegetation and its nickel mine is remarkable because has been a lot of mines becomes French colonialism. People are Melanesian descent and 2. 7\% are Muslim. 


\section{The reason of the construction of the Jean-Marie Tjibaou Cultural Centre}

Construction of this center was to express a Kanak culture to make a decision which the French government during the peace conference after the riots of 1984 and 1988 adopted in New Caledonia. This center, named by Kanak leader who has been killed in 1989. Mr. Piano's design in an international competition to be selected as a chosen design.

Jean-Marie Tjibaou- France New Caledonia Cultural Centre

Design 1991 construction 1993 to 1998

From the distance and among high pines that surrounding the beach, in a glimpse, can be seen the village. This view, in combination with the activities of building construction in the village, provide required motivation for the construction of a new complex. By approaching to this area, reveals the reddish wood and basket-shaped structure of buildings with magical mix of a seemingly ancient situation with primitive and archaic geometry and its ancient forms seems that modern and up to date.

Even obtained great results before the construction of the complex is indicative of a positive response of Piano to showcase New Caledonia Kanak culture that prevails in the region and shows the need and his great interest to rethink and motivate human culture steadily and different shapes. The project also expresses deep insight about the facilities and capabilities of contemporary architecture and how to combine it with the details and intricacies of the local culture. The project is also capable in addition to the missing thinking at the time of restoring the ancient ideas of a people to build a relationship with the surrounding natural environment. (Mousavi, Mir Saeed, 2006)

This people architecture is unique to the wooden-chaffy Cottages, and this is its major limitation of the model for interpretation. Another limitation of this cottage is ephemeral. Kanak local architecture is maintained through the continuation of a specific building practices. Piano response to this issue is kind of architecture that does not defy single building. Complex image from long-distance shows an environmental marks that is complementary and differentiating of beach landscape from far away. The image to be formed of the ten-cottage-like structures in different dimensions. The center has been created from three sections that each section as a native and independent village. Organize the planning sector and circular spaces associated with the Kanak tribe's villages. Methods and materials used to build the cottage like structures are also inspired by this culture. 


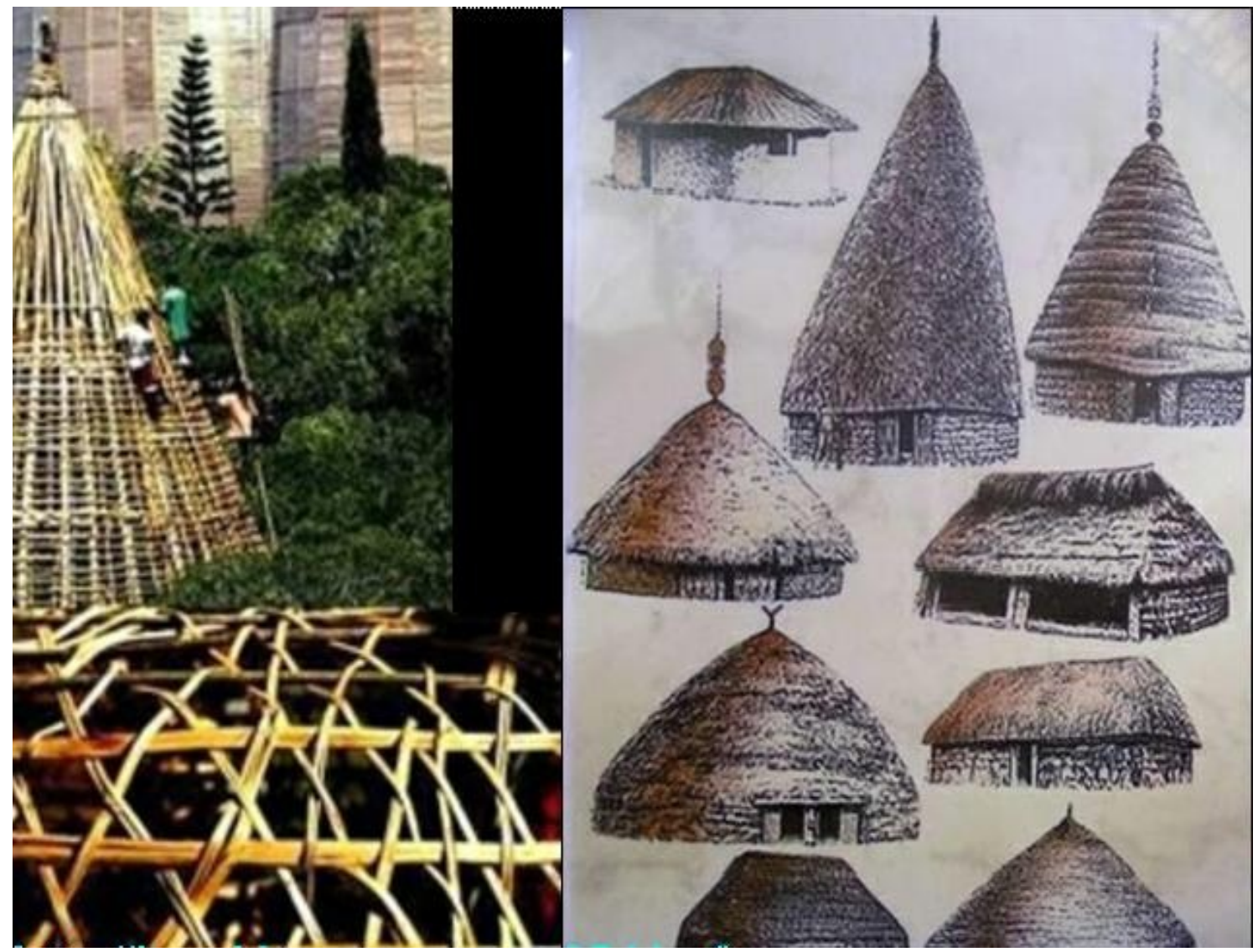

http://iwankhaneyememary 97. blogfa.com/post/28

Piano Art in converting the native structures to high-tech - single layer:

One of the main effects of this collection, executive power in terms of craftsmanship to build them that has rooted in the civilization and region culture. Industry and manufacturing skills that may have crystallized the practices in this area. Structural form of Renzo Piano's to be able incorporated with patterns and abutments forms, braces and other structural elements. The structure of the buildings is double glazed and the gap between walls is considered as valuable tool for cooling and ventilation of the interior. (Mousavi, Mir Saeed, 2006)

Intertwined network with delicate texture, makes up the outer shell of buildings and are differentiated with the vibration in different parts. The outer shell of the building is more dynamic. (Ibid. 100)

\section{Deeper look into 2 project}

If you look deeper into the Chandigarh project and Tjibaou cultural center, we will find that Le Corbusier unwanted ignore some items in Chandigarh that was the failure reason of the project. In Chandigarh can clearly see that Le Corbusier, himself solve all of the problems and because he was afraid of the others opinions affect him and contributing to the project were not consulted with the experience of local people, also the lack of sufficient knowledge of the customs and traditions of the region and ignoring climate and weather conditions that prevailing in that area could be another factor in the failure of Le Corbusier, while Renzo Piano, in the Tjibaou cultural center project be more accurately considered the same things that cause failure in Chandigarh and with precise and comprehensive research and utilization of technician specialists could create successful and exemplary task.

However, if we want to examine on a smaller scale, such as the design for a residential house, the most important thing that the design should be considered is people who had to live in that house, a designer should know what are the needs of residents, their interests and their spiritual understanding, to know 
family customs and bear in mind when designing, a designer must have adequate knowledge of regional climate and also consider climatic factors when designing, so we can say that to get some of this information, need to be consulted with residents and if it does, we can certainly achieve the best plans and architectural drawings for residents and have full compatibility with their spirits. So, building that be constructed that is definitely relaxing place for residents, in this case the proposed hypotheses that have been initially mentioned are accepted.

\section{RESULTS}

Overall, consultation, assistance and interaction that occurs between the designer and project owners, can create a home that has the greatest harmony with their expectations. The designer should always try to design and implement individual ideas and comments with regard to the general framework in the form of appropriate plan that has the all of the issues such as (culture, innovation, localization, climate, etc.) and all of these interactions will yield results which we refer to below.

1. Accepting plans and urban homes by the people: When people are involved in preparing a plan, of course scheme, adapted to their needs, desires, interests and tastes and this increases the acceptability of projects by them.

2. Appropriate knowledge of the culture and way of life of the resident's home and use in home design

2.1 The dynamics and viability of the project will appear in larger neighborhood scale: When the house to be achieved based on sufficient knowledge of the culture and lifestyle of its people in a small area by the designer, the house was consonant with the demands of operation and achieved satisfactory exploitation and in larger urban scale will be less displacement control.

3. Quality of the project: In this regard, it should be argued that the quality of the project should be a different due to regional cultures and building are more favorable and important among the people of an area, if this building was built elsewhere had not been acceptable and vice versa.

4. The importance of the role of people in the design process: It would definitely be said that if Le Corbusier paying more attention to the life of the inhabitants, culture, climate and the importance role of people, did not observe the defeat of Le Corbusier and Abandoned of Chandigarh.

\section{References :}

Eslami Gh et al (Fall 2009, the fine arts magazine. Issue 39)

Parhizgar, Gh. (summer 2003, Hadith publication._Issue 11)

Pourdeihimi Sh. (summer 2011, Journal of Housing and Rural Environment No. 134)

Pirnia, M.K, memarian, GH. Islamic architecture, 1995, Tehran University of Science and Technology, Third Edition.

Khakban, M, Mrjby. Page 20

Dehkhoda, A.A, dictionaries, Page 417

Falamaki, M.M, setting limits on the wealth of culture, in 2005, Feiz published

Holy Qur'an (Surah An-Nahl verse 80)

Kiani, M.Y, history of art and architecture of the Islamic era, in 2005, the seventh edition publication, Tehran

Mousavi, M.S, analysis of works, ideas and insights of Renzo Piano, 2006, Isfahan soil publication

Online resources:

http://.ariyadesign.com

http://iwankhaneyememary97.blogfa.com/post/28 